\section{Influenza Fever Restrictions for Healthcare Workers and Pandemic Planning: Time for Reappraisal}

The Centers for Disease Control and Prevention's thoughtful guidance entitled Prevention Strategies for Seasonal Influenza in Healthcare Settings ${ }^{1}$ states, "Healthcare personnel who develop fever and respiratory symptoms should be: Excluded from work until at least 24 hours after they no longer have a fever." The guidance further states, "Healthcare personnel who develop acute respiratory symptoms without fever may still have influenza infection and should be: Considered for evaluation by occupational health to determine appropriateness of contact with patients." The guidance goes on to state that such healthcare workers be "Allowed to continue or return to work unless assigned to care for patients requiring a protective environment such as hematopoietic stem cell transplant patients." Ridgway and colleagues ${ }^{2}$ found that 20 (49\%) of 41 healthcare workers with influenza A did not report a history of fever or were afebrile when first evaluated for respiratory symptoms, yet $100 \%$ had cough. Yamagishi and colleagues ${ }^{3}$ found that cough started before fever in $10(34 \%)$ of 29 patients with influenza A; sore throat started before fever in $2(29 \%)$ of the 7 patients. Lau and colleagues ${ }^{4}$ found that of 26 patients with influenza $\mathrm{A}$ and 18 patients with influenza $\mathrm{B}$, most had temperatures below $37.8^{\circ} \mathrm{C}$ at the onset of their symptoms (18 [69\%] and 10 [56\%], respectively), yet most had cough (18 [69\%] and 14 [78\%], respectively) and rhinorrhea (19 [73\%] and 11 [61\%], respectively).

The correlation between viral shedding and influenza symptomatology, as well as the influence of viral shedding on influenza transmission, are debated issues. However, Lau and colleagues ${ }^{4}$ found a strong correlation between influenza viral shedding and symptoms. Only $14 \%$ of patients with influenza and detectable virus shedding by reverse transcription polymerase chain reaction were asymptomatic and shedding was low in such cases. However, peak shedding of influenza A virus occurred at symptom onset when only $31 \%$ of such patients had a temperature of at least $37.8^{\circ} \mathrm{C}$.

These studies involve small numbers of patients but share the same signal. The lessons learned are as follows: (1) Fever may be an insensitive identifier for influenza-infected individuals presenting with cough, rhinorrhea, and other respiratory symptoms. (2) Maximal viral shedding occurs at the onset of symptoms, when many influenza-infected individuals are without fever. (3) Maximal viral shedding at the onset of respiratory symptoms suggests that the greatest risk of influenza transmission may in fact occur at that time.
On the basis of these findings, I propose the following recommendations: (1) Healthcare workers should be evaluated for influenza and other respiratory viral infections with otherwise unexplained onset of respiratory symptoms (eg, cough, rhinorrhea, sore throat, nasal congestion) even in the absence of fever. (2) Healthcare workers with influenza, and possibly other viral respiratory infections, should be excluded from work even when they have no demonstrable temperature of $37.8^{\circ} \mathrm{C}$ or higher. (3) Pandemic influenza planners must review their past guidance on the basis of the fact that many patients presenting with influenza do not have fever at symptom onset and may be most contagious at that time. As such, use of fever at airports and in other scenarios for influenza screening will not identify considerable numbers of infectious individuals.

\section{A C KNOWLEDGMENTS}

Financial support. None reported.

Potential conflicts of interest. The author reports no conflicts of interest relevant to this article.

\section{Leonard A. Mermel, DO, ScM, AM (Hon)} FACP, FIDSA, FSHEA

Affiliations: Division of Infectious Diseases, Rhode Island Hospital, and Department of Medicine, Warren Alpert Medical School of Brown University, Providence, Rhode Island.

Address correspondence to Leonard Mermel, DO, Department of Epidemiology and Infection Control, Rhode Island Hospital, 593 Eddy St, Providence, RI 02903 (lmermel@lifespan.org).

Infect. Control Hosp. Epidemiol. 2015;36(10):1248

(C) 2015 by The Society for Healthcare Epidemiology of America. All rights reserved. 0899-823X/2015/3610-0020. DOI: 10.1017/ice.2015.173

\section{REFERENCES}

1. Centers for Disease Control and Prevention (CDC). Prevention strategies for seasonal influenza in healthcare settings. CDC website. http://www.cdc.gov/flu/professionals/infectioncontrol/ healthcaresettings.htm. Updated January 9, 2013. Accessed July 5, 2015.

2. Ridgway JP, Bartlett AH, Garcia-Houchins S, et al. Influenza among afebrile and vaccinated healthcare workers. Clin Infect Dis 2015;60:1591-1595.

3. Yamagishi T, Matsui T, Nakamura N, et al. Onset and duration of symptoms and timing of disease transmission of 2009 influenza A (H1N1) in an outbreak in Fukuoka, Japan, June 2009. Jpn J Infect Dis 2010;63:327-331.

4. Lau LL, Cowling BJ, Fang VJ, et al. Viral shedding and clinical illness in naturally acquired influenza virus infections. J Infect Dis 2010;201:1509-1516. 